\title{
El enfoque de las prácticas: un aporte a la teoría del desarrollo*
}

\author{
Pedro Güell \\ Raimundo Frei \\ Stefano Palestini**
}

\begin{abstract}
Resumen: Los problemas del desarrollo que enfrenta Chile desde aproximadamente una década son cualitativamente diferentes a los que enfrentó en etapas anteriores. El artículo propone una perspectiva conceptual que sea adecuada al tipo específico de desafíos que tiene actualmente el país. Para ello justifica y define la pertinencia de la perspectiva de las prácticas en relación al análisis del desarrollo. En el pasado el principal desafío de la política y de las políticas públicas consistió en cómo diseñar las transformaciones institucionales y de infraestructura necesarias para desencadenar causalmente los cambios sociales pretendidos por las elites. Hoy, en cambio, las dificultades del desarrollo que enfrenta Chile tienen uno de sus principales orígenes en la persistencia o aparecimiento de fenómenos a nivel de la coordinación de la acción de las personas y grupos que no pueden ser ni adecuadamente observadas ni eficazmente intervenidas desde una perspectiva que relegue las prácticas sociales a un segundo plano. Para fundamentar esta tesis, el artículo expone los fundamentos del enfoque de las prácticas a partir de los aportes conceptuales de diversas teorías elaboradas en las ciencias sociales. Dicho enfoque teórico sustentó las indagaciones empíricas contenidas en el Informe sobre Desarrollo Humano 2009.
\end{abstract} tividades

Palabras clave: prácticas sociales, políticas públicas, instituciones, subje-

\section{The perspective of practices: a contribution to the theory of development}

\begin{abstract}
The problems of development faced by Chile since about a decade are qualitatively different from those faced in earlier stages. The article proposes a conceptual perspective that is appropriate to the specific type of challenges that the country currently has. For that, it justifies and defines the relevance of the
\end{abstract}

\footnotetext{
* Este texto sistematiza las reflexiones que sirvieron de base a la elaboración de la perspectiva conceptual del Informe de Desarrollo Humano 2009 del PNUD de Chile, de las cuales los autores formaron parte. Aún cuando toma algunas de las formulaciones de aquél, este texto no representa la opinión del PNUD ni la de los demás miembros del Equipo de Desarrollo Humano, aunque dejamos constancia de nuestro agradecimiento a sus aportes.

** Pedro Güell, Universidad Alberto Hurtado, Santiago, Chile. Email: pguell@uahurtado.cl. Raimundo Frei, Programa de las Naciones Unidas para el Desarrollo, Santiago, Chile. Email: raimundo.frei@undp.org.

Stefano Palestini, Programa de las Naciones Unidas para el Desarrollo, Santiago, Chile. Email: stefano.palestini@undp.org.
} 
perspective of practices in regards the analysis of development. In the past, the main challenge of politics and public policy consisted in designing the institutional and infrastructure changes necessary to causally trigger social changes desired by the elites. Today, the development challenges that Chile faces have as one of its main roots the persistence or appearance of phenomena at the level of coordination of action of individuals and groups that can not be adequately or effectively operated or observed from a perspective that relegates social practices to the background. To substantiate this thesis, the article outlines the foundations of the perspective of practices starting from the conceptual contributions of various theories developed in social sciences. This theoretical approach was on the basis of the empirical research in the 2009 Human Development Report.

Key words: social practices, public policies, institutions, subjectivities

Recibido: 22.06.2009

Aceptado: 15.07.2009

$* * *$

“La práctica es una interpretación continua y una reinterpretación de lo que la regla verdaderamente significa”

(Charles Taylor 1997: 236).

\section{Introducción}

El desarrollo de Chile parece haber alcanzando un límite más allá del cual resulta difícil avanzar. Si se observa con detención se podrá ver que ese límite tiene mucho que ver con las nuevas posibilidades y expectativas del país. Se han alcanzado gran parte de los objetivos del desarrollo -económicos, políticos, sociales y culturales- propuestos hace un par de décadas en el período llamado de la "transición a la democracia". Chile es hoy un país distinto, no sólo en sus realidades sino sobre todo en sus posibilidades: existe un nuevo piso de oportunidades, mayores expectativas y demandas. Esto crea desafíos de un nuevo tipo. Ellos ya no pueden abordarse con los mismos instrumentos de la etapa anterior, aún si fueron muy aptos para enfrentar las tareas de esa época. El país ha cambiado de escala en los desafíos del desarrollo y para seguir avanzando se requiere en muchos ámbitos nuevas perspectivas, políticas e instrumentos ${ }^{1}$.

Este cambio de perspectiva demanda, primero, observar los límites que tiene el enfoque que ha predominado hasta ahora en la definición de las estrategias de desarrollo para actuar eficazmente frente a las nuevas realidades sociales. Si bien es cierto que en estas últimas tres décadas se han implementado estrategias de desarrollo con énfasis distintos y políticas públicas de diversa inspiración, subyace a ellas, y muchas veces a las más exitosas de entre ellas, un modo común de definirlas e implementarlas. En

${ }^{1}$ Güell (2006 y 2007). 
ese período ha predominado un pensamiento lineal, jerárquico y tecnocrático. Es una manera particular de pensar cómo ocurren los cambios en la sociedad y cómo se hacen realidad las oportunidades.

Segundo, se hace necesario precisar cuáles son las nuevas dinámicas que hoy tienden a definir los cambios y las realidades del desarrollo. Como indica el Informe de Desarrollo Humano 2009 elaborado por el PNUD de Chile, en el corazón de las nuevas tendencias se encuentra la creciente importancia de las relaciones cotidianas a través de las cuales los actores persiguen sus objetivos materiales y subjetivos. Por esta razón, es en las prácticas concretas -a veces impredecibles y a veces ancladas en pesados hábitos- donde se hacen realidad o se frustran las oportunidades de la sociedad. Es ahí, por tanto, donde hay que buscar algunos de los nuevos desafíos de esta etapa del país y obtener criterios para la elaboración de los instrumentos y políticas adecuados a ellas.

El actual cambio de escala que enfrenta el país no significa que antes no existieran desafíos provenientes de las prácticas cotidianas. Tampoco significa que haya que pasar de estrategias "de arriba hacia abajo" centradas en el Estado, hacia políticas "de abajo hacia arriba” centradas en la participación y en los problemas triviales de la gente. En la historia de Chile, como en la de cualquier sociedad, siempre existieron prácticas cotidianas y ellas jugaron un rol decisivo en la formación de las dinámicas efectivas de la vida social. Del mismo modo, en el futuro seguirá existiendo el Estado, las instituciones y las élites técnicas, y ellas seguirán jugando un rol clave en el desarrollo. Lo que cambia son sus pesos relativos, la relación entre ellas y el tipo de perspectiva que se requiere para vincularlas eficazmente.

Reconocer la importancia de las prácticas cotidianas no es el único desafío del desarrollo en Chile, ni su insuficiente consideración es la única explicación de sus obstáculos. Es una dimensión entre otras. Pero una que no ha recibido suficiente atención. Tomarlas en cuenta no sólo enriquecerá el debate sobre el desarrollo humano, también contribuirá a poner en su centro el reconocimiento de que las nuevas dinámicas sociales demandan nuevas maneras de pensar y ejecutar los cambios sociales.

El objetivo de este artículo es, primero, vincular los actuales desafíos del desarrollo de Chile, especialmente el aprovechamiento de sus nuevas y auspiciosas oportunidades, con un diagnóstico sobre las nuevas tendencias del cambio social. Segundo, fundamentar la pertinencia de una teoría de las prácticas para comprender mejor las posibilidades de acción en el nuevo escenario. Con estos fines se desarrolla una caracterización del tipo de escenario pasado y de las perspectivas que se usaron para abordarlo, aquello que denominamos "pensamiento lineal" en un contexto de predominancia de los "problemas de entorno". Luego se exponen los fundamentos y conceptos principales de una perspectiva de las prácticas y su pertinencia frente al nuevo contexto. Se trata de un esquema de elementos 
conceptuales que provienen, como se mostrará, de las distintas teorías de las prácticas elaboradas en las ciencias sociales.

\section{Los límites del pensamiento lineal ${ }^{2}$}

Puede parecer paradojal que aquellas maneras de definir la sociedad chilena, las miradas estratégicas y los instrumentos que sirvieron para promover uno de los períodos de desarrollo más exitosos en la historia del país, comiencen ahora a perder eficacia y, en algunos casos, a transformarse derechamente en fuente de frustraciones. Pero no lo es tanto si se considera que el país cambió. Las apuestas de ayer sobre qué es lo que permitía el desarrollo de Chile, descansaban sobre unos supuestos que en buena parte ya no rigen hoy en día, precisamente porque las antiguas estrategias fueron eficaces y lograron provocar en gran medida el cambio que se esperaban.

Las transformaciones en la fase de transición a la democracia descansaron sobre supuestos y apuestas de diverso tipo. No parece posible reducirlas a una formula única. Sin embargo, en el ámbito específico de las definiciones acerca de cómo es posible provocar y conducir cambios en la organización de la vida social puede sugerirse que ese período se caracterizó por el predominio casi exclusivo de un pensamiento lineal, jerárquico y tecnocrático entre las élites que definían las estrategias de desarrollo y las políticas públicas.

El “pensamiento lineal” define las dinámicas de la vida social como el resultado de relaciones de causa y efecto relativamente constantes, delimitables y reconocibles. Afirma que si se conocen esas relaciones se podrá modificar sus resultados mediante intervenciones que tendrán un efecto predecible, directa y proporcionalmente vinculado a estas. Sólo basta entonces un buen conocimiento de la realidad, decisión y recursos para que la realidad se amolde a la intención de los programadores. Esa idea, algo simplificada aquí, parte del supuesto de que los actores sociales son un eslabón más en la cadena de causas y efectos, que reaccionan más o menos de la misma manera frente a los mismos estímulos y que tienden a adaptarse pasivamente a las exigencias de esas cadenas con el fin de satisfacer sus necesidades. Ese pensamiento es lineal precisamente porque apuesta a que un estímulo en el punto inicial de la cadena produce efectos predecibles hasta el final de ella.

Así, por ejemplo, en los inicios del período de la transición, se supuso en el ámbito educacional que si se modificaban correctamente los contenidos curriculares, se construía la infraestructura donde aquellos pudieran

\footnotetext{
${ }^{2}$ En el último tiempo son varios los autores que han llamado la atención sobre la particularidad y los límites del pensamiento lineal, entre otros IADB (2006); Mayntz (2005); Sharpf (1997); Waissbluth (2008).
} 
ser adecuadamente enseñados y se proporcionaban los instrumentos didácticos correctos, entonces el resultado sería un aprendizaje de mayor calidad, en línea con lo propuesto en el curriculum. Se supuso que los actores a los cuales iban destinadas esas reformas interpretarían su sentido de la misma forma como quienes los habían programado, adaptarían sus intereses al nuevo contexto ofrecido y reaccionarían de acuerdo a lo previsto. Consecuentemente se dejó de lado las interpretaciones particulares que aquellos harían, el modo en que jugarían sus estrategias y sus tácticas para defender sus identidades y posiciones adquiridas. También se les restó importancia a las fuerzas, tanto internas como externas al sistema escolar, que daban inercia a las maneras tradicionales de enseñar y aprender.

El pensamiento lineal supone también que existe un actor central que tiene los conocimientos, los recursos y las voluntades necesarias para mover a la sociedad. Gracias a eso él tiene la capacidad para "programar" el desarrollo y la acción pública, ajustado las causas y los incentivos correctos para provocar los resultados esperados. Por lo mismo, supone también que la sociedad está organizada como un todo jerárquico. Eso es lo que lo autoriza a pensar que a partir de las iniciativas de comando y control central se pueden intervenir diversos aspectos de la realidad y que éstos reaccionarán de manera coordinada y coherente con el plan. Finalmente, se supone que los beneficiarios de las políticas del programador lineal tienen la misma racionalidad e intereses que éste, por eso debieran interpretar sus señales con el mismo sentido que él les dio.

Como puede verse, el pensamiento lineal es mucho más que la propuesta de una metodología de planificación social. Es, en rigor, una imagen de la sociedad, de sus cambios y de las formas de acción de sus miembros. Ella es expresión y soporte de la imagen fuertemente arraigada en Chile de que son las élites estatales y tecnocráticas las que definen por vía de autoridad y de manera relativamente autónoma y voluntarista las dinámicas de la sociedad. Más que los éxitos de su instrumental técnico, es la pervivencia de esa imagen de sociedad la que le ha dado su reiterada vitalidad al pensamiento lineal.

Por causa de sus supuestos, el pensamiento lineal siempre ha tenido limitaciones para provocar cambios en el sentido esperado. Como supone un tipo de actores y de relaciones entre ellos muy idealizados, tiende a pasar por alto los comportamientos reales de las personas y la particularidad de las situaciones en las que ellos actúan. No se toman en cuenta muchas fuerzas reales que imprimen su sello a los procesos reales de cambio, como la persistencia de maneras de hacer las cosas muy arraigadas histórica y culturalmente en la sociedad chilena La consecuencia suele ser que aparecen efectos inesperados que distorsionan los cambios programados.

A pesar de esta debilidad, hay desafíos sociales frente a los cuales el pensamiento lineal tiene eficacia. Especialmente en ámbitos de baja complejidad, donde los problemas presentan un carácter fácilmente delimitable y frente a los cuales se dispone de abundante información, alta capacidad 
de control y fuertes consensos acerca de lo que hay que hacer. Normalmente se trata de problemas donde las relaciones sociales juegan un rol secundario. A esos desafíos se les puede llamar "problemas de entorno". Entre estos se encuentran iniciativas como la construcción de infraestructura, la ampliación de cobertura de ciertos servicios como la electricidad, el riego o la mejoría de la infraestructura escolar.

Pero también existen desafíos que no se comportan de esa manera, frente a los cuales el pensamiento lineal muestra fuertes limitaciones. Se trata de problemas de alta complejidad, que resultan de cambios recientes y, por lo mismo, no disponen de suficiente conocimiento acumulado. Suelen ser ámbitos muy densos en relaciones y significados sociales, donde están presentes actores con relativa autonomía entre sí y existen centros múltiples y difusos de control. Frente a estos desafíos, que están sometidos a fuertes cambios, poseen alta densidad de relaciones y representan problemas inéditos, las instituciones reducen su capacidad de regulación. A este tipo de desafíos se les puede llamar "problemas de lógica de acción”, pues su núcleo problemático radica precisamente en la organización de las relaciones entre los actores. Son problemas tales como la mejoría de la calidad educacional a través de la modificación de los comportamientos en el aula, o la operacionalización de derechos de atención en salud, la promoción del emprendimiento y la cultura de la innovación o la transformación de las relaciones laborales en los lugares de producción.

El actual cambio de escala que atraviesa el país puede caracterizarse precisamente por el paso del predominio de los "problemas de entorno" al de los "problemas de lógica de acción”. La posibilidad de avanzar en el desarrollo pasa cada vez menos por los primeros y cada vez más por los segundos. Es más, muchos problemas que en el pasado eran de "entorno", y fueron resueltos exitosamente orientados por el pensamiento lineal, hoy se tornan problemas de "lógica de acción", frente a los cuales aquel es claramente insuficiente. Así, por ejemplo, si hasta hace poco construir una central hidroeléctrica era un asunto principalmente técnico que podía ser definido por la voluntad de los gobernantes, y legitimado por cálculos científicos, económicos y por los marcos legales -como fue el caso de la central Rapel en los años sesenta-, hoy ello se ha vuelto un escenario de disputas sociales, donde un número importante de actores diversos posee competencias y poderes para cuestionar las decisiones políticas, técnicas o legales. Como lo han mostrado los casos de Ralco y Aysén, incluso cuando de trata de construir represas parece necesario partir construyendo relaciones sociales, sin que exista un solo actor, un solo lugar o un solo instrumento que pueda lograrlo por sí solo y donde las soluciones siguen vías que no son precisamente lineales.

A pesar de que el enfoque lineal tiene unos límites internos, que se han acentuado en el nuevo contexto del cambio de escala, a veces se confunde su pérdida de eficacia con la reducción de la capacidad de la sociedad y de sus actores para actuar sobre la marcha del desarrollo. Pareciera sugerirse que ya que no se puede actuar eficazmente como hasta ahora, 
entonces no se puede actuar del todo. Por esta vía, la crisis del voluntarismo tecnocrático se transforma en pesimismo social.

Las actuales dificultades del desarrollo tienen uno de sus orígenes, no el único, en la persistencia o aparecimiento de fenómenos a nivel de la lógica de acción de las personas y grupos que no pueden ser ni adecuadamente observadas ni eficazmente intervenidas desde la perspectiva del pensamiento lineal imperante, ni desde las lógicas de conducción social que se derivan de él. Se trata de mostrar la importancia creciente de aquel punto ciego que adquiere cada vez mayor importancia: las prácticas reales de los actores. Es cierto que estas ponen nuevos obstáculos a las estrategias hasta ahora exitosas, pero abordarlas adecuadamente es una de las vías indispensables para seguir avanzando en el desarrollo.

Los cambios culturales, políticos e institucionales, aquello que hemos llamado cambio de escala, ponen en el centro los desafíos de las lógicas de acción, gracias a las cuales los individuos se relacionan y se coordinan de las maneras concretas en que lo hacen. Mientras los problemas de entorno remitían a la cobertura, al campo institucional o la legitimidad discursiva de la libertad, hoy las prácticas aparecen relevantes cuando se desea mejorar la calidad de la implementación, la gestión, los procedimientos a través de los cuales se operacionaliza una lógica de derechos en los servicios públicos, cuando se pretende innovar en una empresa o se desea llevar a cabo biografías autónomas.

\section{El espacio de las prácticas}

Para comprender por qué las oportunidades de la sociedad se traducen unas veces en resultados exitosos, otras en inesperados o frustrados, hay que partir de un hecho sencillo: las acciones de las personas. La realidad de la sociedad, incluyendo sus aspectos abstractos y generales como las leyes, ideologías o estructuras, o hechos tan difusos como los temores y aspiraciones de sus miembros o tan concretos como la producción y distribución de bienes, se verifica y tiene consecuencias sólo si los individuos actúan. Este es el punto inicial del enfoque de las prácticas. ${ }^{3}$

\footnotetext{
${ }^{3}$ Son múltiples los autores que han trabajado el concepto de prácticas. Se encuentra en la filosofía antigua, medieval y moderna, desde Aristóteles a Heidegger, y por supuesto en Wittgenstein; en la sociología clásica y contemporánea; en el nuevo institucionalismo de la ciencia política; en las nuevas generaciones de la Escuela de los Anales, es decir, en casi todas las humanidades. Para el caso de este artículo se han utilizado diversas fuentes, casi todas del ámbito de la sociología, que sirven de referencia a este trabajo. Sin embargo, no hay ningún autor que se siga fielmente y de todos se han extraído ideas y conceptos, pero no necesariamente su estructura argumental. Algunos de estos autores son: Archer (1995); Bourdieu (1972 y 1980); De Certeau (1990); Foucault (1980); Giddens (1979 y 1984); Joas (1996); Knorr Cetina (2001); Reckwitz (2002); Schatzky (1997, 2001, 2002 y 2006); Swidler (2001); Taylor (1995); Thévenot (2001); Turner (2001). El texto no discute ni sus semejanzas ni sus diferencias con estas teorías.
} 
Pero cuando los individuos actúan no deciden de manera espontánea ni plenamente libre qué hacer en cada caso. Esto implicaría varios supuestos que no son realistas, como por ejemplo, que los individuos se coordinan espontáneamente de modo cooperativo entre sí por el sólo hecho de que cada uno persigue libremente sus fines. Lo cierto es que las acciones de las personas están enmarcadas y orientadas por hechos preexistentes en la vida común, como las instituciones y sus normas, el lenguaje o la distribución de los bienes. Son esos hechos sociales los que aseguran, mejor o peor según el caso, que puedan coordinarse la multiplicidad de intereses y acciones de los miembros de la sociedad.

Pero la acción de los individuos tampoco es un simple reflejo de las normas y estructuras de la sociedad. Afirmar esto supondría que los individuos sólo tienen en su conciencia y en sus intereses las reglas y necesidades de la sociedad y no tienen capacidad para tomar cierta distancia frente a ellas. O que las normas y mecanismos sociales tienen capacidad para definir las acciones de las personas incluso frente a la más específica y puntual de las situaciones. En las personas existe un grado de autonomía para definirse a sí mismas, lo que quieren y cómo quieren obtenerlo; es lo que puede denominarse como subjetividad personal.

Ni las instituciones objetivas de la sociedad ni la subjetividad bastan, cada una por sí sola, para que los actores organicen su acción y sus relaciones con otros. Para actuar se requieren ambas. Por una parte, las personas no pueden satisfacer sus necesidades sino actuando coordinadamente con los demás. Esto exige que existan previamente algunas reglas que aseguren ciertos grados mínimos de coherencia y predicción a esas relaciones. Eso es precisamente lo que proporciona la organización institucional de la sociedad. Por la otra parte está la necesidad vital de las personas de poseer un grado de autonomía y de identidad propia para darle un sentido a su actuar. Esto es lo que aporta la subjetividad.

Aunque se requieren instituciones y subjetividades para hacer posible la acción de las personas, entre ellas no hay necesariamente correspondencia sino más bien tensión. Por un lado, la forma en que la sociedad organiza sus reglas, le da sentido a sus normas o distribuye sus recursos no coincide plenamente con todas las necesidades definidas por las propias personas. Por el otro, las subjetividades personales no siempre encuentran en las instituciones de la sociedad los soportes para hacer efectiva su autonomía y darle un sentido propio a sus proyectos. En esto consiste la tensión entre sociedad e individuo: para hacer posible la coordinación de muchos actores, la sociedad debe traducir las situaciones particulares a reglas generales y la subjetividad, por el contrario, debe dotar de sentidos individuales y concretos las normas sociales.

La tensión entre sociedad e individuo ha variado a lo largo de la historia. La sociedad moderna se caracteriza precisamente por la amplitud que ha alcanzado esa tensión. Esto ocurre por dos movimientos que van en dirección opuesta. Por una parte, la complejidad y variabilidad de las rela- 
ciones sociales a escala global demanda hoy un tipo de instituciones muy abstractas y muy independientes respecto de las intenciones de los actores o de las situaciones puntuales en las que ellos actúan. Piénsese, por ejemplo, en el sistema financiero global que regula un factor clave en las interacciones económicas de miles de millones de actores repartidos por todo el mundo. Por la otra, los cambios culturales y políticos han llevado a una acentuación de la individualización y de la autonomía en el modo de pensar y actuar de las personas. Ello puede observarse en la valoración del riesgo y la creatividad individual, en la promoción de los derechos ciudadanos, en la publicidad del consumo o en la promoción del emprendimiento.

Ahora bien, en toda sociedad las tensiones entre las reglas y las intenciones personales dejan abierto entre ellas un espacio de ambivalencias e incertidumbres que debe ser cerrado. Sin un grado importante de articulación entre ambas no es posible asegurar la coordinación entre varios actores. Son las relaciones entre las personas las que logran establecer esos vínculos. En esto consisten principalmente las prácticas; no tanto en seguir las reglas de la sociedad o las orientaciones de la subjetividad, sino en construir maneras de hacer las cosas que hagan posible un vínculo entre las exigencias y propuestas de las instituciones y de las subjetividades.

Tanto la subjetividad como las instituciones requieren de esos procesos de articulación, no sólo porque existen tensiones entre ellas, sino también porque no se bastan por sí mismas. Las instituciones requieren dejar un cierto grado de libertad y riesgo para que los individuos puedan ensayar acciones frente a situaciones o necesidades inéditas. La subjetividad requiere cierto grado de estabilidad en las relaciones sociales para poder constituirse como tal.

Las prácticas sociales son, precisamente, esos procesos de articulación. Son las maneras de actuar y relacionarse que despliegan los actores reales en espacios concretos para satisfacer sus necesidades. Una práctica es, por ejemplo, la manera en que actúan y se relaciona el personal médico, los pacientes y los administrativos en un recinto hospitalario para satisfacer las distintas necesidades implicadas en el proceso de tratar enfermedades. $\mathrm{O}$ las formas tradicionales en que se busca y encuentra a la pareja matrimonial. O las estrategias que establecen los trabajadores de una fábrica para resistir las presiones de la gerencia para obtener aumentos sostenidos de la productividad.

En todos estos casos las prácticas son posibles gracias a la existencia de instituciones y de subjetividades que aportan reglas, recursos, identidades y sentido a las acciones. Pero además, las prácticas tienen una inercia y una tradición propia que dota a los individuos que participan de ella de un sentido rutinario y común en su actuar. Al mismo tiempo hacen posible procesos de aprendizaje que permiten incorporar y estabilizar soluciones exitosas ante problemas nuevos.

En los puntos que siguen se describirán los tres principales fuerzas 
estructurantes de las prácticas: las instituciones, la subjetividad y las inercias que derivan de su conocimiento práctico. El conjunto de estas fuerzas y las tensiones que se generan entre ellas le proporcionan a la práctica una estructura básica y un conjunto de alternativas nunca plenamente coherentes ni nunca totalmente contradictorias. La estructuración del espacio de las prácticas es un espacio de posibilidades, no un mapa de acción definido. La acción tiene un grado de independencia respecto de esa estructuración, pero sólo es posible gracias a ella.

\section{Las instituciones ${ }^{4}$}

Las instituciones son aquel conjunto de reglas formales que definen lo que se puede o debe perseguir como fines de la acción en un espacio de prácticas. Son reglas que definen y distribuyen, entre los potenciales participantes de ese espacio, recursos, roles, poderes y lenguajes, encauzando de esta manera los cursos de acción. Su principal aporte es proveer un marco general de orientaciones y recursos relativamente estables que permite que las personas y la sociedad obtengan resultados predecibles. Las instituciones reflejan estructuras de poder y la forma en que la sociedad distingue y segmenta a los actores sociales. Ellas reproducen clases y estratos sociales, etnias, géneros, centros y periferias, elites y masas. Por esta razón las instituciones juegan un rol muy decisivo en la definición de las posibilidades y restricciones de las prácticas.

La teoría institucionalista suele distinguir los tipos de instituciones según si estas son formales o informales. Las instituciones formales son normas explícitas y positivamente estatuidas que incluyen desde la Constitución de la República, hasta los contratos que regulan las relaciones entre empresarios y trabajadores. Las instituciones informales, por su parte, son conocimientos tácitos transmitidos por la sociedad y son parte de la cultura; incluyen convenciones, reglas morales y pautas de comportamiento. La diferencia fundamental entre ambos tipos de instituciones radica en cómo se generan y sancionan. Las instituciones formales son creadas por procedimientos establecidos y su sanción es llevada a cabo por dispositivos autónomos y organizados como, por ejemplo, los tribunales. Las instituciones informales, en cambio, son generadas al interior de las prácticas sociales y se sancionan por la fuerza inercial de las costumbres, por la presión del grupo, o por las motivaciones intrínsecas de sus integrantes. En lo que sigue se usará el concepto de institución sólo para las instituciones formales.

Las instituciones estructuran las prácticas en varios sentidos. En primer lugar, asignan recursos a través de la definición legal de derechos para

\footnotetext{
${ }^{4}$ Sobre la relación mutuamente condicionada entre instituciones y acción veáse Dubet (2006); Giddens (1979 y 1984); Ghezzi and Mingione (2007); March y Olsen (1993 y 1997); Mayntz (2005); North (1990); Scharpf (1997); Schatzky (2006); Schelzky (2007); Sen (1999); Wagner (1994); Willke (1997 y 2006); Zurbriggen (2006).
} 
su utilización. En segundo lugar, las instituciones establecen los roles de los distintos actores (por ejemplo, directores, supervisores, madres, padres, intermediarios, beneficiarios, etc.), definiendo sus diversas atribuciones, capacidades y su poder institucional. En tercer lugar, generan sistemas de incentivos que orientan la acción de los actores hacia determinados fines, motivando ciertas conductas por sobre otras, sobre la base de beneficios por cumplimiento o castigos por incumplimiento.

Si bien las prácticas no pueden desarrollarse prescindiendo de la asignación de recursos, la definición de roles y el establecimiento de incentivos, esto no significa que las prácticas estén completamente determinadas por su marco institucional. Recursos, roles e incentivos son interpretados, intercambiados y redefinidos en los distintos juegos que componen la dinámica de las prácticas. El rol de enfermera puede estar altamente formalizado en el reglamento de un hospital, pero en la práctica ese rol puede adquirir atribuciones por completo diferentes a aquellas estipuladas en su contrato. Lo mismo es válido para los sistemas de incentivos. Estos son interpretados por el conocimiento práctico, son dotados de sentido por la subjetividad de los actores y son negociados en las relaciones que constituyen los espacios de prácticas.

Las instituciones varían en el nivel de alcance que tienen respecto al espacio de prácticas que regulan. Existen instituciones más generales que definen reglas obligatorias para todos los miembros de la sociedad, como la Constitución de la República, la que señala incluso cómo y por quién puede ser creada cualquier otra institución. Hay también algunas que regulan y aportan recursos para ámbitos específicos, como la Jornada Escolar Completa, la regulación de la compra y venta de acciones o las Garantías Explicitas en Salud. Hay otras que no se derivan directamente de los órganos políticos superiores, sino que proceden de ámbitos sociales relativamente autónomos. Las reglas del fútbol elaboradas por la ANFP, el sacramento del matrimonio de la iglesia católica, o las normas de comportamiento ético de un colegio profesional son instituciones de este tipo. También existen instituciones supranacionales, dictadas por órganos donde están representados los distintos Estados, como Naciones Unidas o la Organización Mundial del Comercio. Entre estas instituciones se encuentran los derechos humanos y sus convenios, las regulaciones aduaneras y migratorias o los acuerdos medioambientales.

Debido a esta diversidad de instituciones y alcances, es que en un mismo espacio de prácticas operan, simultáneamente, muchas instituciones. Teóricamente las reglas de todas ellas debieran ser coherentes entre sí, pero ese no suele ser el caso. Lo normal es que el marco institucional de una práctica esté compuesto por señales con algún grado de contradicción por las propias instituciones que influyen en ella. A ello se suma que al interior de cada institución no siempre existen coherencias entre las normas dictadas y los recursos asignados. Ello indica que el marco institucional de un espacio de prácticas, no sólo es general y abstracto por necesidad propia, sino que además posee ciertos grados de incoherencia, desajustes y conflictos. 
Debido a la necesaria generalidad que requieren para regular espacios de prácticas diferentes y por sus contradicciones, las instituciones no pueden regular eficazmente las acciones con el nivel de precisión y especificidad que requieren las relaciones entre actores en las situaciones concretas. Para ello son necesarias organizaciones que operacionalizan las reglas institucionales y administran sus recursos e incentivos en cada espacio específico de prácticas. La ley del consumidor no basta por sí misma para asegurar que alguien que ha comprado un producto defectuoso pueda reemplazarlo por otro. Para eso son necesarias oficinas, personal especializado, formularios, buzones de reclamo, etc. Tampoco basta el diseño del modelo de transporte urbano "Transantiago" para que la ciudad se mueva de acuerdo a él. Requiere tecnologías de intercambio de información y seguimiento de los buses, entrenamiento a los conductores y a los usuarios, mecánicos y carabineros que controlen el uso de las vías exclusivas.

Las ambivalencias y tensiones del marco institucional y organizacional han aumentado en el último tiempo con el cambio de escala que vive el país. A esto ha contribuido la mayor diversidad de instituciones de distinto nivel que operan en un mismo espacio -lo cual ha recibido un fuerte impulso desde el proceso de globalización-, la mayor variedad de posibilidades organizacionales y la diferenciación de espacios de prácticas cada vez más específicos. Mientras más grande es la ambivalencia, mayor es el trabajo de articulación que deben realizar las prácticas y más amplia es la independencia que estas adquieren para definir su forma concreta. Esto también influye en la creciente autonomía de las prácticas y la importancia de las formas de coordinación y configuración de las maneras de hacer las cosas.

\section{Las subjetividades ${ }^{5}$}

En el otro polo del espacio de las prácticas está la subjetividad. Si por el lado de las instituciones se representa la construcción del mundo social desde la perspectiva de su estructura general -un mundo "para todos"-, la subjetividad personal representa la definición de una perspectiva propia desde la cual organizar y apropiarse del mundo como algo con sentido "para mí". Subjetividad remite a un individuo con necesidades, emociones y capacidad de percibir, interpretar y comunicar y que define sus intereses e identidades en las relaciones con otros. La subjetividad remite al portador concreto de la acción: un individuo que define su identidad e intereses con los otros en juego.

La subjetividad no nace con el individuo: surge en sociedad y es sostenida por ella. La subjetividad se construye en las relaciones con los

\footnotetext{
${ }^{5}$ Cfr. Beck (1994; 1997 (ed.)); Beck y Beck (2001); Dubet y Martuccelli (1996); Foucault (2001); Elias (1987); Giddens (1991 y 1992); Goffmann (1963 y 1974); Güell (1999 y 2001); Habermas (1988); Lechner (1999 y 2002); Martuccelli (2002 y 2007); PNUD (2002); Reckwitz (2006); Simmel (1971).
} 
otros, con los cuales se aprende lo que es común a todos y lo que es propio. La formación de la subjetividad ocurre gracias a las sociabilidades primarias. Es en la familia, los amigos, el barrio, la iglesia, en algunos casos en la escuela o el club deportivo donde se adquieren los rasgos más generales y básicos que definen la cultura en la cual se vive. Allí se aprenden las reglas fundamentales del lenguaje, el disciplinamiento del cuerpo y de las emociones, la capacidad para verse con los ojos de los demás, la habilidad para reconocer las distinciones básicas que ordenan el espacio social (los que mandan y los que obedecen, lo bueno y lo malo, lo feo y lo bello, los extraños y los semejantes). Ese proceso es el que habilita la pertenencia social de los individuos.

Sobre esa base aquellos elaboran una identidad subjetiva. En sus relaciones con los diversos grupos primarios a los que pertenecen, los individuos hacen experiencias diversas de su pertenencia y de su diferencia respecto de ellos. El trabajo de construir para sí una identidad subjetiva consiste en elaborar un sentimiento y un relato relativamente coherente de la especificidad propia en el marco de la pertenencia a esos grupos, de la permanencia de un sí mismo pese a los cambios de todo tipo que se experimenta, de la apertura al futuro pese a la historia recorrida.

La identidad subjetiva nunca está plenamente acabada, siempre queda puesta a prueba de nuevo por las nuevas relaciones en que se participa. Por ejemplo, una mujer va definiéndose por el lugar donde nació y estudió, por las organizaciones donde trabaja, por la experiencia de la maternidad y su relación con sus hijos, por sus amigas o las asociaciones en que participa, o por las relaciones que establece para el uso de su tiempo libre. En este sentido, la subjetividad se forma como una historia, los individuos van construyendo sus biografías en el tiempo. Pero el sentido de sí mismo formado al calor de los grupos primarios durante la infancia y la juventud constituye el piso básico y relativamente estable desde donde las personas enfrentan los desafíos que les presentan las diversas prácticas en las que actúan.

Nadie puede desarrollar y realizar su identidad subjetiva al margen de sus prácticas concretas, pero no todos pueden resolverlo exitosamente, ni todas las prácticas se prestan para ello. Las diferentes prácticas en que participa una persona tienen distinta capacidad para servir de soportes a las identidades. Desde esta perspectiva, las prácticas son un espacio de trabajo biográfico y pueden ser evaluadas según su capacidad para ser soporte u obstáculo de aquél

Las identidades subjetivas son también una fuerza que delimita las alternativas de acción en el espacio de las prácticas, pues definen la estructura motivacional de los actores: los gustos, preferencias y los intereses desde donde buscan coordinar sus relaciones con los otros, demandan su reconocimiento, establecen límites para los roles que se les proponen e interpretan los incentivos y fines disponibles.

Hoy los procesos de formación de identidades personales se han 
vuelto difíciles. Los grupos de sociabilidad primaria han perdido parte de su fuerza como referentes que permiten definir un sentido de pertenencia y de diferencia. No sólo se vuelven más escasos, como las relaciones en los barrios, las iglesias, los clubes, los partidos políticos. También se vuelven más inestables, como ocurre con la familia. Y son menos coherentes en su cultura interna, como ocurre con todos los anteriores.

Al mismo tiempo, en la actualidad los individuos se ven presionados a diferenciar cada vez más su identidad subjetiva. La globalización, que expone todas las diferentes identidades posibles al mismo tiempo gracias a los medios de comunicación globales, ha sido un importante motor de este proceso. De esta manera, hoy los individuos deben singularizar fuertemente sus identidades al tiempo que disponen de menos relaciones primarias fuertes que les sirvan de espejo y les ayuden a delimitarse. Esto hace que la formación de las identidades subjetivas sea un proceso difícil de cerrar satisfactoriamente o que a veces derive en formas anómalas, y ello es un factor que influye sobre el curso que toman las prácticas. Tal como las instituciones se vuelven más abstractas y cambiantes, así también la subjetividad se vuelve más volátil y fragmentada.

\section{Conocimiento Práctico ${ }^{6}$}

Lo que las personas hacen y ponen en juego en una práctica -como se definen a sí mismos y a los demás, cómo y para qué usar los recursos disponibles, qué es deseable, tolerable e inaceptable en cada situación- se transforma con el paso del tiempo en un conocimiento práctico que cada participante lleva consigo y que tiende a estabilizarse en el tiempo. El conocimiento práctico actúa como si fuesen mapas que guían a los transeúntes en una ciudad. Se trata de mapas inscritos en diversos planos y profundidades de la conciencia individual. Algunos segmentos de él son inconscientes, otros son reflexivos, otros están inscritos en los movimientos corporales. Un militar que topa a otro de rango mayor no requiere sacar un manual de operaciones para saber que hacer; su cuerpo ya lo "sabe”, se lleva la mano a la frente velozmente y saluda.

El conocimiento práctico sedimenta maneras de hacer las cosas, vuelve inerciales conductas y acciones. Su carácter rutinario le confiere su trayectoria histórica a la práctica, pudiendo sobrevivir a campañas de educación y comunicación destinadas a su modificación. Esto ocurre así porque su vigencia no se debe a su coherencia lógica, a su verdad científica o a su corrección moral. Su autoridad proviene que sedimenta y organiza acciones y disposiciones que de hecho resultan significativas para los actores, sea por razones pragmáticas, simbólicas o simplemente rutinarias. La autoridad de un conocimiento práctico es reflejo de la eficacia de la práctica misma y no al revés. Hay quienes “saben” como “coimear” a otros; pue-

${ }^{6}$ Cfr. Bourdieu (1972 y 1980); Collins (2001); Knorr Cetina (2001); Turner (2001). 
de ser irracional o inmoral, pero ese conocimiento es verdadero mientras permita obtener los resultados que se persiguen con la coima. Esta eficacia no depende del conocimiento mismo, sino de cómo se comportan recíprocamente los actores en una práctica en que se usa el soborno.

Los mapas del conocimiento práctico son muy resistentes al cambio porque proveen de un mundo seguro por el cual transitar, es decir son reductores de incertidumbre. El conocimiento práctico permite desarrollar expectativas ante los otros y sus posibles conductas, o anticipar que irá a pasar en una situación específica. Cuando se conduce un automóvil, se espera que el otro respete la luz roja y de este modo, uno pueda cruzar la calle sin problemas. No es de extrañar, por tanto, que los cambios culturales o institucionales generen resistencia y eleven la incertidumbre en la práctica, pues desafían los mapas de expectativas sedimentados en las mentes y los cuerpos de los actores.

A pesar de su gran resistencia, el conocimiento práctico suele ser desafiado por los cambios que se desarrollan en la sociedad actual. Por ejemplo, los aprendizajes adquiridos hace algunos años sobre tecnologías ya no bastan para utilizar la tecnología actual, se vuelven obsoletos con los nuevos productos que requieren maneras diferentes de relacionarse con la tecnología. Usar un "personal - stereo” suponía un conocimiento bastante diferente al que requiere actualmente un iPod y las relaciones sociales que se establecen a partir de ambos dispositivos son también diferentes a partir del hecho de que el último de ellos opera gracias a la existencia de las redes virtuales. También afecta a la estabilidad del conocimiento práctico la fragmentación y la diversificación de actividades que desarrollan los individuos en una sociedad moderna, las que empujan a la elaboración de conocimientos rutinarios para actividades que muchas veces se contradicen entre sí.

Por cierto, y esto forma parte de la experiencia cotidiana, siempre se puede innovar en las prácticas. Es más, a veces es vital hacerlo, pues ni el conocimiento práctico ni las rutinas son suficientes para dominar perfectamente las situaciones, especialmente en períodos de cambio acelerado. En un contexto de cambio de escala, en que las maneras tradicionales de hacer las cosas no dan los resultados esperados, la innovación siempre será uno de los activos más importantes para alcanzar metas más altas. La innovación no obedece fórmulas estandarizadas, sin embargo es más probable que se transformen en realidad aquellas innovaciones que hacen sentido en el marco de las rutinas y conocimientos preexistentes. En una empresa un nuevo sistema de administración tiene más esperanza de adaptarse entre los trabajadores antiguos, si ellos reconocen dentro de su ámbito de conocimiento práctico las nuevas modalidades que se le ofrecen. También tienen más posibilidades de desarrollarse aquellos conocimientos prácticos que recogen y organizan las experiencias reiteradas de éxito en el enfrentamiento de problemas desconocidos, aunque ellas hayan sido inicialmente fruto del azar. Esto es lo que puede denominarse como el "aprendizaje" de las prácticas. 
En síntesis, puede sugerirse que si la misión de las instituciones es orientar a las acciones de los actores particulares con un sentido de generalidad para darle mayor probabilidad a la coordinación entre ellos, la función de las identidades subjetivas es dotar a las acciones regidas por reglas generales de un sentido propio. Porque sirven a intereses en parte opuestos, ambas misiones no se complementan fácilmente y dejan abierto un campo amplio y ambivalente de posibilidades de acción. Por eso es que los actores deben desarrollar entre ellos maneras propias de hacer las cosas que les permitan coordinarse y poder así realizar sus objetivos. Con el tiempo y la rutina esas maneras de hacer las cosas se estabilizan y se convierten en un conocimiento práctico que delimita las opciones futuras y las posibilidades de cambio. Por su parte, las experiencias inevitables de cambio pueden conducir a nuevas formas de estabilización mediante procesos de aprendizaje.

Instituciones, identidades subjetivas y conocimiento práctico estructuran el espacio de las prácticas; son, por tanto, elementos imprescindibles para que éstas se puedan desarrollar. Sin embargo, como ya se ha mencionado, las prácticas también presentan cierta autonomía respecto a sus marcos de delimitación. Este grado de autonomía es histórico y depende de las condiciones materiales y culturales de cada sociedad. Como regla general, la autonomía cobra particular relevancia cuando aumenta la complejidad de las instituciones y las subjetividades.

Mientras mayor sea la incoherencia entre instituciones, y entre estas y las organizaciones que las implementan, mayor será la posibilidad de que en las prácticas entren a jugar factores que alteran el desarrollo de los objetivos formales. Lo mismo puede decirse de las identidades subjetivas. Cuando estas son fuertes, fundadas en la conciencia de sus derechos, en el valor de su particularidad, en la tolerancia hacia las demás y en el reconocimiento de su interdependencia con otros, aumenta la capacidad de los actores para participar pro activamente en las prácticas e intentar cambiar la manera tradicional de hacer las cosas. Por el contrario identidades fragmentadas o inseguras promueven disposiciones defensivas y desconfiadas, que tienden protegerse en un conocimiento práctico que les de seguridad y confianza.

El cambio de escala que está experimentando Chile representa un escenario de mayor complejidad, con una creciente importancia de las dinámicas prácticas que explican el modo de relacionarse y coordinarse en una sociedad. En este sentido, no basta con conocer los elementos que estructuran externamente una práctica, también es necesario una mirada analítica que reconozca las dinámicas y juegos que construyen desde dentro las lógicas concretas de las acciones efectivas.

\section{La dinámica de las prácticas}

En la vida cotidiana cada uno transita por diversos espacios de práctica, de la casa a la oficina o la fábrica, de los lugares de esparcimiento al 
supermercado. En todos ellos no se percibe en el día a día las reglas y los incentivos institucionales, ni los procesos de formación de identidad, ni los diversos mapas prácticos que permiten moverse con seguridad. Pero todos estos elementos están en juego en todo momento y permiten que las personas se relacionen unas con otras.

Para poder jugar un partido de tenis se necesita la cancha, los conocimientos de sus reglas y los objetos que hacen posible el partido (las redes, las pelotas, las raquetas), sumado a los jugadores y el conocimiento adquirido por parte de ellos de cómo jugar. Sin embargo, si se toman estos elementos aisladamente, no se puede jugar. Sólo cuando se ponen en movimiento las reglas del juego, los jugadores y sus estrategias, y los objetos del partido, los elementos entran en relación y se actualizan en diversos juegos prácticos. Los juegos son, pues, la puesta en marcha de los factores que estructuran un espacio de prácticas.

Existe una variedad muy amplia de juegos que se superponen y se influencian recíprocamente en las distintas actividades de la vida cotidiana. Se puede decir que así como los juegos son relaciones dinámicas de reglas, objetos y actores, las prácticas son relaciones dinámicas de juegos. Son precisamente estas relaciones dinámicas que ocurren en los juegos, las que hacen que las prácticas nunca puedan ser completamente determinadas por las subjetividades e instituciones que intervienen en ellas.

Analíticamente se pueden distinguir diversos tipos de juegos, algunos más relevantes en la dinámica de una práctica que en otra. Aquí se revelaran sólo algunos, pero que parecen ser los más importantes.

\section{Las prácticas son juegos de identidades ${ }^{7}$}

Los juegos de identidades consisten en la relación de adecuación, negociación y conflicto entre las diversas identidades presentes en un determinado espacio de prácticas. Entre los roles formales propuestos por las instituciones y las identidades de los actores reales, y entre las identidades de éstos. Aunque una práctica nunca supera del todo las tensiones entre identidades, para que pueda desarrollarse con cierto nivel de eficacia requiere alcanzar un grado importante de compatibilidad y reconocimiento entre ellas.

Las instituciones y las organizaciones proponen roles formales para organizar socialmente las prácticas de los actores. Los roles no sólo dicen qué acciones debiera ejecutar cada uno de ellos, sino también señala cómo debe relacionarse con todos los demás participantes. Se supone que un con-

\footnotetext{
${ }^{7}$ Cfr. Bourdieu (1972 y 1980); Dubet y Martuccelli (1996); Foucault (2001); Giddens (1991 y 1992); Goffman (1963 y 1974); Martuccelli (2002 y 2007); PNUD (2002); Schatzky (2002); Sennett (2000).
} 
junto de roles bien definidos en el papel y coherentes entre sí permiten que una organización obtenga sus fines como un todo y cada miembro sus fines particulares. Pero ese no es el caso normal. En los sistemas de roles de una organización suele existir un grado importante de ambivalencias e imprecisiones. Además los roles formales deben ser actuados por personas reales y sus identidades subjetivas, las que nunca calzan perfectamente en los roles que se les propone o impone. Estos hechos abren el espacio para que deba desarrollarse un juego de negociación y redefinición de los roles reales que imperan en una práctica.

La articulación entre identidades subjetivas y roles no es un asunto privado entre uno mismo y el rol propuesto; es al mismo tiempo un juego de negociaciones entre varios actores. Todos los que trabajan en una fábrica negocian sus roles y parte de esa negociación depende como los demás negocian los suyos. Un trabajador cuya identidad subjetiva lo impulsa a actuar como líder en su empresa y a buscar reconocimiento como tal por parte de los demás trabajadores, tendrá que negociar o imponer redefiniciones al rol formal que se le propone, el cual probablemente no contempla ese matiz o tal vez lo excluye. Pero simultáneamente tendrá que negociar con todos lo demás en esa sección para que acepten su liderazgo. A su vez esto afecta los procesos de negociación de sus propios roles formales por parte de aquellos, que tal vez no contemplan el matiz de acatar las directrices de un líder informal. Los juegos de identidad afectan a todos y definen las interacciones reales que constituyen una práctica.

Los roles formales y las identidades tienen, sin embargo, un límite en su tolerancia a ser redefinidos. El rol de operario de una maquina puede adquirir en la práctica muchas otras especificaciones, pero probablemente no aquellas que dicen que puede mandar al gerente. Con las identidades subjetivas pasa algo similar, no cualquier rol es tolerable para una identidad subjetiva dada. Un jefe de obra que tiene miedo a las alturas, tendrá dificultades de hacerse cargo de la construcción de un edificio muy alto. Pero dentro de esos límites hay muchas posibilidades por ambos lados. Cual sea el arreglo al que se llegue dependerá de los poderes respectivos y de las coherencias de los marcos institucionales y de la nitidez de las identidades. De esta manera, las prácticas reales no se definen por los roles formalmente descritos en el organigrama, ni por lo que a cada uno le gustaría ser, sino por las atribuciones y relaciones que se establecen de hecho en el juego de las identidades que tiene lugar dentro de los límites y tolerancias descritas por los marcos institucionales y subjetivos.

Las definiciones de las identidades y roles que se generan en los juegos prácticos pueden sedimentarse en el conocimiento práctico, generándose identidades estereotipadas muy resistentes a posteriores redefiniciones. Cuando esto sucede los distintos actores tienden a anticipar el comportamiento del otro atribuyéndole una identidad permanente. Un adolescente, por ejemplo, puede anticipar la respuesta de su padre si este tiene un carácter autoritario, ocultándole su vida privada. 
En los juegos de identidad no sólo resultan alterados los roles formales, también las identidades sufren modificaciones. Cada vez que un individuo se le presenta un nuevo rol, el va actualizando su identidad de acuerdo a las nuevas experiencias. Así por ejemplo, cuando se entra a trabajar por primera vez, o se tiene la experiencia de la paternidad y la maternidad, las biografías cambian.

Estas nuevas experiencias permiten ir realizando las identidades y modificándolas durante el tiempo. Los individuos no sólo deben negociar sus identidades en cada práctica específica, por ejemplo al interior de la fábrica o del hospital, sino que deben al mismo tiempo trabajar la coherencia entre las distintas identidades que resultan de las múltiples prácticas en las que se desenvuelven, por ejemplo, la familia, los amigos, la pareja, la ciudadanía política, el consumo, etc.

Este último proceso reviste actualmente una gran complejidad. Hoy la distancia entre las identidades subjetivas, cada vez más diversas e individualizadas, y los roles formales, cada vez más especializados, tiende a ser más amplia que antes. Además las personas tienden a participar en una mayor cantidad de prácticas. Lo anterior significa que el trabajo de articulación de identidades y roles es mayor y los resultados más inciertos tanto para las personas como para las organizaciones en que se desenvuelven. Hoy las personas han adquirido mayor autonomía e individualidad en la construcción de sus identidades, pero ha aumentado el trabajo que tienen que hacer para organizarlas. Esto tiene consecuencias para las práctica; o bien se vuelven más inestables porque las negociaciones de identidad se hacen permanentes o bien recurren al autoritarismo para imponer identidades fijas.

\section{Las prácticas son juegos de poder ${ }^{8}$}

Los juegos de poder son la puesta en movimiento de los recursos institucionales y de las capacidades subjetivas por parte de los actores. A través de ellos los actores compiten por aumentar sus recursos, así como por adquirir reconocimiento para sus identidades y proyectos.

La distribución de poder tiene dos fuentes distintas. Por un lado, el poder surge de los recursos y distinciones procedentes del marco institucional de la práctica. Un gerente puede instalar un sistema de bonos de producción según metas, porque tiene los atributos formales para distribuir recursos y organizar relaciones. Por el otro, el poder también surge de la capacidad individual para llevar adelante las intenciones y deseos particulares. Este poder subjetivo depende de la auto-percepción sobre el valor de la identidad individual y de las redes y relaciones que se posee para sustentar-

${ }^{8}$ Cfr. Bourdieu (1972 y 1980); De Certeau (1990); Foucault (1980); Martuccelli (2002); PNUD (2004); Araujo (2009). 
la. Por ejemplo, en la misma empresa que se ofrecen los bonos, un líder informal de los trabajadores puede imponerse entre éstos para que no cumplan más que las metas mínimas, con el fin de mantener una estructura dada de salarios y limitar la competencia entre el personal. En este sentido, entre poder institucional y subjetivo no siempre hay correspondencia, ya que las relaciones y distribuciones reales de recursos y reconocimientos estarán dadas por el tipo de poderes prácticos que se ponen en juego en cada situación.

En los juegos del poder pueden, además, reconocerse dos formas de acción: acciones estratégicas, cuando existen actores que cuentan con suficiente poder real (institucional o subjetivo) para imponer un diseño de la práctica misma, y acciones tácticas cuando los actores sólo cuentan con poder para obtener ventajas al interior de los resquicios de una práctica definida por otros. Un adolescente podrá desarrollarse tácticamente en su familia si las reglas son muy firmes, mientras que podrá actuar estratégicamente en las fiestas con sus amigos si tiene un fuerte poder subjetivo. Cualquiera sea la diferencia entre estos espacios, no hay un actor que posea todo el poder, ni otro que posea nada. Todos los actores poseen algún poder práctico y la suma final del juego entre ellos puede diferir de circunstancia en circunstancia.

El trabajo que todos hacen para articular sus identidades subjetivas con los roles formales que les asigna el marco institucional también está atravesado por los juegos de poder. Aquellos que están en posición estratégica tienen mayor capacidad para adaptar sus roles formales a las necesidades de sus identidades subjetivas que aquellos que están en posición táctica. Por sus diferencias de poder, tanto cultural como institucionalmente delimitadas, a los hombres les resulta más fácil que a las mujeres articular roles e identidades subjetivas. Esto ocurre, por ejemplo, en el trabajo a través de su capacidad para definir los horarios y lugares de reunión o los lenguajes que se usan en ellas. Gracias a eso a los hombres les es más fácil validar sus identidades como tales en el trabajo.

Lo anterior señala que los juegos de poder en las prácticas tienen también una dimensión simbólica. Muchas veces las prácticas son construidas de tal forma que permitan representar y reproducir diferencias de poder y distinciones sociales. La desigualdad que existe en la relación entre el dueño de un predio agrícola y una temporera, o la subordinación que hay entre un médico y su paciente no siempre son un resultado inesperado del funcionamiento imperfecto de las organizaciones. Muchas veces es al revés, se organiza las prácticas de manera tal de representar las desigualdades y distinciones prevalecientes, independientemente de si ellas son funcionales a los fines formales perseguidos. Esta distinción es relevante pues muchas veces se atribuye a un defecto de organización o a un efecto inesperado lo que en realidad es un hecho que delimita intencionalmente las prácticas.

La distribución de los espacios físicos o de los uniformes en una oficina, por ejemplo, tal vez no tenga ninguna utilidad funcional pero sea altamente eficaz para representar las diferencias de poder o las distinciones 
entre los funcionarios. Es probable que esas distribuciones de bienes simbólicos no estén definidas en ningún reglamento formal. La organización simbólica de las prácticas tiende a tener gran independencia de los marcos formales y está muy influida por las identidades y por las inercias históricas. La fuerza del rol simbólico de las prácticas limita seriamente las posibilidades de organizar racionalmente las prácticas en función de los fines explícitamente perseguidos.

\section{Las prácticas son juegos de intercambio ${ }^{9}$}

En las prácticas se juega también relaciones de intercambio, donde los distintos actores llegan acuerdos en los cuales transan distintos objetos o beneficios que son útiles para ambas partes de la relación. Se puede intercambiar trabajo, tiempo, lealtades, compromisos, protección, información, reconocimiento, etc.

En estos juegos toma forma el principio de reciprocidad: se da, se recibe, se devuelve. Se concede a un funcionario que salga antes, a fin que el devuelva las horas perdidas. Un padre le da permiso a su hijo para que juegue computador, a cambio que el haga las tareas. Un profesor deja espacio de recreación en las clases a cambio que los alumnos pongan atención un momento. Los juegos de intercambio crean una dependencia entre los participantes de la práctica, dado que los que reciben generalmente están obligados a devolver.

El “dar, recibir, devolver" que define los juegos de intercambio toma la forma de un doble compromiso. Por un lado, es una relación de dependencia en la que los actores depositan su confianza en el respeto recíproco del acuerdo. Por el otro, se trata de una relación de deuda, en la que el actor que recibe queda "endeudado" con el que da. Este doble carácter del intercambio genera una relación de poder entre quien da el don inicial y el que recibe la deuda.

Algunas relaciones de carácter estrictamente económico se configuran como juegos de intercambio. Como cuando un empleador intercambia el respeto a las condiciones laborales mínimas de un trabajo decente, por el compromiso de sus trabajadores de no sindicalizarse. En este caso, lo que debiera entenderse como un derecho es concebido en la práctica como un bien de intercambio.

Las relaciones de intercambio dentro de las empresas y oficinas son de vital importancia para visualizar los mecanismos no contractuales. En ella se efectúan pactos y lealtades, premios y castigos, que pueden ser vinculantes para la dinámica total de la organización, pero que no se pue-

${ }^{9}$ Cfr. Bourdieu (1972 y 1980); Levi - Strauss (1950 y 1966); North (1990); Mauss (1950); Ostrom (1990); Schatzky (2002). 
den inscribir en los términos formales del acuerdo. Un jefe de obra puede premiar a ciertos obreros con un trabajo más liviano, si le respetan su autoridad y sus reglas. También, se puede intercambiar apoyo político por protección, como en el caso de un funcionario que apoya a un líder informal a cambio de que él lo apoye para obtener ciertos cargos o recursos.

La reciprocidad que se establece hace que los actores sientan que pertenecen a algo en común, generando relaciones de complicidad frente a otros actores que no participan del juego. En una familia, la hija puede intercambiar secretos con su madre a fin de tener permisos de salida. $\mathrm{O}$ en una empresa, trabajadores y empleadores pueden actuar como cómplices para burlar a un inspector del trabajo si el jefe bonifica a fin de mes. En estas relaciones de complicidad puede suceder que uno de los actores cómplices resulte perjudicado contraviniendo, por ejemplo, normas que en definitiva lo protegen.

El compromiso de reciprocidad se fundamenta en el entendido que los participes de la relación ganan un bien para ambos. Dentro de una escuela, el autoritarismo de un director puede ser avalado por los profesores en la medida que el primero no supervise las clases de los últimos. El primero gana poder y legitimidad, el segundo aprovecha que nadie evalúe sus rendimientos de calidad. Es por ello que el contravenir el compromiso -no pagar la deuda- es duramente sancionado en la práctica. Cuando uno de los actores rompe el compromiso, dicho acto es interpretado como una deslealtad, rompiendo la relación y poniendo en riesgo toda la vinculación y los bienes que genera la práctica.

Los juegos de intercambio se ven sometidos a tensiones cuando lógicas de derecho introducen mecanismos de supervisión y control, o cuando los actores tienen más conciencia de lo que pierden al someterse a una deuda que les perjudicará a futuro. En este sentido, la mayor demanda de derechos ciudadanos hacia los sistemas de supervisión pública o la necesidad de mejorar la gestión del campo público y privado, son signos que ponen a prueba dinámicas de intercambio que no se ajustan a los desafíos actuales de la sociedad chilena.

\section{Las prácticas son juegos de información ${ }^{10}$}

Los juegos de información consisten en la puesta en movimiento y circulación de los conocimientos necesarios para actuar en un determinado espacio de prácticas. Si bien, los mapas mentales que componen el conocimiento práctico tienen amplias zonas detalladas y compartidas entre sí, lo que hace posible la coordinación entre los distintos actores y la perpetua-

${ }^{10}$ Cfr. Bourdieu (1972 y 1980); Collins (2001); Giddens (1984); Goffman (1963 y 1974); Knorr Cetina (2001); Schatzky (2002 y .2006); Taylor (1995) ; Thévenot (2001); Turner (2001). 
ción de la práctica en el tiempo, también existen zonas con asimetrías de información, ya sea porque algunos actores poseen un conocimiento técnico del cual otros carecen, o bien porque el acceso a ciertas parcelas del conocimiento están parcial o completamente denegados. Los juegos de información cobran importancia precisamente por estos diferenciales de conocimiento.

En la práctica de negociación entre un empleador agrícola y un obrero para establecer los términos del contrato uno tiene mayor acceso que el otro a las señales del entorno de esa práctica, como la probabilidad de una sequía en las zonas agrícolas del hemisferio norte y su impacto en el precio de la cosecha, y tiene mayor capacidad para interpretar las consecuencias pragmáticas de ese hecho para el desarrollo de la negociación salarial. Esto le da una ventaja estratégica para ajustar las prácticas en función de sus necesidades e identidades y para aprovechar las oportunidades que surgen del entorno. El nivel de información contenido en el mapa de conocimiento de una práctica y las capacidades para interpretarla suelen estar muy desigualmente distribuidas. Las asimetrías de información pueden generar pérdidas de eficiencia en los juegos de intercambio, pues puede generar altas cuotas de desconfianza recíproca.

En muchos espacios de prácticas toman lugar saberes expertos que permiten a ciertos actores llevar a cabo acciones de mayor complejidad y sofisticación. Generalmente, distintos juegos de información pueden combinarse para crear un objetivo que individualmente sería imposible. Por ejemplo, en la construcción de un edificio, tanto la información que maneja el arquitecto, el albañil, el jefe de obra, el que maneja la obra son diferentes, pero se coordinan para llevar a cabo un fin común. La información que contiene cada uno por sí sólo no bastaría para llevar a cabo la obra.

Los juegos de información también fortalecen ciertos roles y poderes institucionales. Aquellos que poseen una información de alta calidad técnica, pueden a partir de su conocimiento adquirir posiciones o aspirar a cargos de gran poder. Un médico con alta especialización puede postular a jefe de pabellón, o un profesor universitario de mucha calidad a jefe de departamento. $\mathrm{Y}$ en sus relaciones con los otros pueden denotar el prestigio y la autoridad que les da su saber.

Sin embargo, el saber experto está cada vez más tensionado en las prácticas, debido, por una parte, al mayor acceso de los actores a información y conocimiento a través de las nuevas tecnologías de la comunicación y la información, con lo que la brecha entre los distintos actores tiende a acortarse o a cuestionarse. También la mayor instucionalización y publicitación de algunos procedimientos (como en la justicia o en la salud) deja a ciertos actores sin un poder discrecional. Por último, los actores y las organizaciones modernas se perciben cada vez más capaces y con mayor derecho a exigir una transparencia en los procedimientos y en la información que las instituciones contienen, como demanda a una sociedad que sabe que la información es poder. 


\section{El cambio de las prácticas ${ }^{11}$}

Hay muchos factores que tienden a hacer rutinarias y a estabilizar las prácticas: las identidades, los poderes en juego, las complicidades en los intercambios, la desigualdad de la información, etc. Si se las mira desde ese ángulo podría parecer que ellas casi no cambian. Pero lo cierto es que también hay muchas fuerzas que empujan a las prácticas a cambiar, aunque lo hacen a velocidades particulares, por factores no siempre controlables y en direcciones no siempre previsibles.

Las prácticas son constelaciones de relaciones sociales mediadas por una multiplicidad de factores, tanto externos, como los diseños institucionales y cambios culturales, o internos, como los juegos de las prácticas. Cuando cambia alguno de esos factores, tienden a verse afectados los otros y, con ello, surge una presión para el cambio del conjunto de la práctica. Analíticamente se puede distinguir entre las presiones de cambio que provienen del exterior de las prácticas, específicamente de sus marcos institucionales y de la formación cultural de la subjetividad, y los cambios que se generan desde el interior de las prácticas mismas, como consecuencia de pequeñas variaciones en los juegos prácticos, o por procesos de reflexión y aprendizaje internos.

Los cambios externos, institucionales o subjetivos, gatillan reacciones en las prácticas cuya dirección dependerá del procesamiento que hagan los juegos que integran la práctica. Por ello se puede decir que las prácticas son relativamente autónomas de los cambios provenientes de los marcos que la delimitan. A continuación se describirán algunas de las dinámicas del cambio de las prácticas.

\section{Las presiones al cambio que provienen de las instituciones y la subjetividad}

Por razones puramente convencionales se puede partir por los factores externos para describir las dinámicas de cambio. En ese plano se ubican las estructuras institucionales y culturales. A través del sistema decisorio público -el Estado y sus distintas agencias- se crean o modifican instituciones, presionando modificaciones en los juegos prácticos a través de redefiniciones de roles o cambio en los sistemas de incentivos.

También pueden existir cambios al nivel de las organizaciones que hacen concretas a las instituciones. Los cambios organizacionales también son intencionales pero no necesitan ser sancionados por el sistema decisorio público, pudiendo cambiar incluso sin que cambien las instituciones a las que sirven; por ejemplo, cuando se introducen nuevas formas de cobrar

${ }^{11}$ Cfr. Archer (1995); Giddens (1979 y 1984); Joas (1996); Luhmann (1997); Schatzky (2001 y 2002); Willke (1997 y 2006). 
impuestos como resultado de la aplicación de nuevas tecnologías y formas de gestión que no requieren cambios en la ley.

Los cambios institucionales u organizacionales crean nuevas restricciones y posibilidades para las prácticas. Aportan nuevos recursos, o nuevas formas de distribuir los antiguos, nuevas reglas y roles, etc. El efecto de los cambios institucionales u organizacionales sobre las prácticas no es directo ni lineal. Dependerá de su propio grado de coherencia, de los poderes que acompañen su cumplimiento y del comportamiento del resto de las fuerzas en juego, especialmente de las identidades y necesidades de los actores.

Las presiones al cambio de las prácticas pueden provenir también del lado de la subjetividad. Las transformaciones culturales pueden debilitar antiguas identidades y promover otras nuevas en los individuos, y con ello facilitar nuevos tipos de relaciones sociales. El debilitamiento de las identidades políticas o religiosas, así como la expansión de la individuación, la conciencia de derechos, la pertenencia a tribus son ejemplos de este tipo de cambios. Ellos pueden modificar los posibles roles que los actores pueden adoptar en el seno de las prácticas.

El surgimiento de la conciencia de dignidad autónoma en los niños -un cambio del entorno cultural-, así como las nuevas leyes sobre violencia intrafamiliar -un hecho del entorno institucional- han introducido cambios en las relaciones de padres e hijos y en las prácticas familiares, como por ejemplo prohibir formalmente y sancionar socialmente el uso de la violencia. Esto no significa que haya desaparecido la violencia familiar contra los niños, pero ella tiene más restricciones que antes. Y eso presiona a la redefinición de los roles reales que los actores juegan en las prácticas, condicionando con ello a las prácticas mismas.

Además de las presiones de cambio provenientes de las instituciones y de la subjetividad, se pueden reconocer estímulos provenientes de entornos lejanos de las prácticas. Una crisis financiera en un país extranjero puede generar una oleada de variaciones en los comportamientos bursátiles y de la economía real que se propaga por distintos espacios de prácticas. Algunas de estas oleadas de cambio pueden generar modificaciones institucionales, afectando, por ejemplo, las políticas fiscales o monetarias de un país, y a través de ellas presionando al cambio de prácticas. Pero también pueden presionar directamente las prácticas, por ejemplo el cambio en los precios internacionales de los alimentos puede llevar a los productores a modificar sus prácticas de contratación, congelando acuerdos colectivos o despidiendo trabajadores.

\section{La irritación del entorno}

Las modificaciones de los factores externos crean "irritaciones" en las prácticas y éstas no pueden dejar de reaccionar. Sin embargo, los acto- 
res y factores de una práctica no reaccionarán automáticamente, sino según sus juegos internos. Por ejemplo, la introducción de la evaluación docente obligatoria puede tener distintos efectos sobre las prácticas de relación entre los profesores y el ministerio de educación. Ella puede ser interpretada como mecanismo de fortalecimiento de la labor pedagógica o como mecanismo de debilitamiento de derechos gremiales. Ambas alternativas pueden tener consecuencias muy diferentes sobre la evolución de las prácticas. Si es posible una u otra interpretación dependerá de la formulación de la ley y de su operacionalización organizacional; si se impone una u otra interpretación dependerá de los juegos de poder y de identidad que se impongan en la práctica, por ejemplo la fortaleza del gremio, las identidades predominantes entre los profesores o el rol de los sostenedores.

Se pueden reconocer distintos tipos de reacción de las prácticas. A continuación se mencionan algunos de ellos. Un primer mecanismo de reacción consiste en la renegociación de identidades. Ante la presión por los cambios se suelen redefinir el mapa de los roles, sus funciones y quiénes pueden ocuparlos. El aumento de exigencia sobre la calidad de las escuelas para que estas produzcan mejores resultados académicos, puede llevar a un cambio en los términos de referencia del director, o a acentuar más las atribuciones del coordinador técnico-pedagógico o tal vez a contratar un psicólogo. A veces surgen roles inesperados, como un apoderado que asume tareas de liderazgo informal ante una crisis en la escuela. Cuál de estas modificaciones se haga dependerá de factores internos, como las luchas de poder, el tipo de recursos en cuestión y las interpretaciones predominantes de la situación. El resultado en cualquier caso es variable, desde una modificación real de la dinámica y del producto de la práctica hasta una simple labor cosmética que refuerza los trazos generales de la manera habitual de hacer las cosas.

La forma en que los actores reaccionan ante las variaciones del entorno puede dar lugar a la reproducción de prácticas previas. Puede ocurrir que ante cambios que son interpretados como una amenaza o ante situaciones de fuerte incertidumbre, los actores busquen refugiarse en las reglas más básicas y conocidas de la práctica en cuestión. Se trata de una suerte de regresión a las certidumbres básicas; proceso que, además, suele estar acompañado de una validación no razonada de esas certidumbres, pues para que ofrezcan refugio frente a los cambios deben quedar puestas fuera de toda duda. Las regresiones defensivas tienden a reforzar maneras autoritarias de hacer las cosas.

También pueden ocurrir reacciones de tipo adaptativo, proponiendo pequeños cambios pero conservando lo esencial de la práctica. Siguiendo una distinción expuesta más arriba, pueden darse adaptaciones estratégicas -cuando sirven a los intereses de los actores con poder y afectan a muchos-, o tácticas -cuando los actores más débiles persiguen su propia supervivencia. 


\section{Los cambios que provienen de las prácticas mismas}

Las prácticas también pueden cambiar como efecto de procesos internos y estos pueden ser de distinto tipo. En primer lugar está el ensayo y error. Las desviaciones o las pequeñas variaciones internas introducidas por los actores al repertorio habitual, sea de manera consciente o no -como en el caso de los accidentes o las casualidades - , pueden dar por resultado más o mejores productos, o mejores reacciones a los cambios del entorno. Probablemente una sola variación, por exitosa que ella sea, no basta; se requiere una suma de ellas sostenidas en el tiempo como para juntar la suficiente experiencia que amerite su estabilización en las rutinas y su inscripción en los mapas del conocimiento práctico.

En segundo lugar está la imitación de maneras de hacer las cosas en el espacio de otras prácticas. Ellas pueden adoptarse por razones pragmáticas o simbólicas, como apropiarse del prestigio que se les atribuye a ciertas maneras de comportarse. Puede ocurrir también un traslado involuntario de prácticas, como cuando un actor o grupo de ellos al desplazarse de manera estable de una práctica a otra traslada sus mapas cognitivos originales y los reproducen en el nuevo espacio. Puede tratarse de grupos migratorios o de desplazamientos entre sectores de la industria o entre el sector público y privado.

Finalmente, existen las innovaciones y aprendizajes. Se trata de procesos reflexivos de creación de nuevos roles y relaciones entre ellos, nuevos sentidos para la acción, nuevas interpretaciones del entorno que permiten articular de mejor manera las señales institucionales, las identidades subjetivas, los recursos y los fines compartidos. Las innovaciones y los aprendizajes no son procesos espontáneos, sino que requieren de la creación de un ambiente favorable, entre cuyos rasgos se cuenta la horizontalidad de las relaciones sociales, la fluidez de las comunicaciones, la tolerancia ante las desviaciones y la aceptación del fracaso.

\section{Conclusión}

Este artículo parte de la tesis que los problemas del desarrollo que enfrenta Chile actualmente son cualitativamente distintos a los que debió enfrentar en otros períodos de su historia. No son sólo desafíos más complejos o más numerosos, sino que se trata de problemáticas que se encuentran a una escala diferente a la anterior. Este cambio de escala ha sido expresado en este trabajo como el tránsito de problemas de entorno -aquellos que se pueden controlar, programar e intervenir desde instituciones tecnócratas- a problemas de lógicas de acción, que sólo pueden ser visualizados e intervenidos con un enfoque analítico que visualice las formas de coordinación de los actores en las prácticas concretas.

El enfoque de las prácticas, no implica un olvido de las instituciones ni un menosprecio de su función en la organización de las sociedades. Por 
el contrario, implica reconsiderar el efecto de las instituciones en la acción e interacción de actores en contextos específicos. Esto significa comprender que las instituciones no ejercen presión lineal sobre la acción, sino que establecen normas e incentivos que son interpretados y cargados de nueva significación por parte de los actores. El gran aporte del enfoque de las prácticas para la teoría del desarrollo consiste en brindar un marco conceptual que permita vincular el nivel institucional de la sociedad con el nivel de la subjetividad de los actores, y comprender como varía este vínculo complejo y problemático- a lo largo del tiempo.

Desde esta mirada, la práctica no puede ser entendida como mera conducta. Las prácticas son las maneras de relacionarse de actores en un espacio estructurado por las instituciones y organizaciones de la sociedad, por la subjetividad elaborada por cada actor en sus trayectorias biográficas, y por los mapas y rutinas que constituyen la memoria de la práctica o, como se ha llamado en este trabajo: el conocimiento práctico. Un primer paso para aplicar el enfoque de las prácticas consiste en identificar estos distintos elementos y su participación en espacios sociales concretos. Pero no basta con esto. Un segundo paso fundamental es reconstruir las dinámicas que ponen en movimiento dichos factores. Es lo que se ha denominado como juegos prácticos.

En los juegos de identidad, poder, intercambio e información, las prácticas cobran un alto grado de autonomía y de refracción a las irritaciones del entorno institucional. Sólo observando empíricamente las formas particulares que adoptan dichos juegos prácticos es posible comprender el fracaso de algunas políticas y la dirección inesperada que han tomado otras, así como las transformaciones en las identidades y representaciones de ciudadanos y ciudadanas.

Precisamente ese ha sido el propósito del Informe sobre Desarrollo Humano 2009, "la manera de hacer las cosas". Hacer uso del enfoque de las prácticas para reconstruir los "modos de hacer las cosas” en espacios concretos de la sociedad chilena: la implementación de políticas públicas, las prácticas laborales y las prácticas de construcción biográfica. No se trata tanto de una "nueva mirada”, sino más bien, de observar los viejos problemas de la sociología, pero con el lente nuevo de las prácticas sociales. 


\section{Bibliografía}

Araujo, K. (2009), Habitar lo social: Usos y Abusos en la vida cotidiana en el Chile actual, LOM, Santiago de Chile.

Archer, M. (1995), Realist social theory: Realist social theory: The morphogenetic approach, Cambridge, New York.

Beck, U. (1994): “The debate on the "Individualization Theory” in Today’s Sociology in German” en Soziologie Special Edition, págs.191-200

Idem (2002 [1997]), Hijos de la libertad, Fondo de Cultura Económica, México D.F.

Beck, U. y Beck-Gernsheim, E. (2003 [2001]), La individualización. El individualismo institucionalizado y sus consecuencias sociales y políticas, Paidos, Barcelona.

Bourdieu, P. (1977 [1972]), Outline of a theory of practice, Cambridge University Press, United Kingdom.

Idem (1990 [1980]), The logic of practice, Stanford University Press, California.

Collins, H. M. (2001), "What is tacit knowledge” en Schatzky, T (ed). The practice turn in contemporary sociology, Routledge, Londres.

De Certeau, M (1999 [1990]), La invención del cotidiano, Universidad Iberoamericana, México D.F.

Dubet, F. (2006), El declive de las instituciones, Gedisa, Buenos Aires.

Dubet, F. y Martuccelli, D. (1998 [1996]), En la escuela, Losada, Madrid.

Elias, N. (2000 [1987]), La sociedad de los individuos, Península, Barcelona.

Foucault, M. (1980), La microfísica del poder, La piqueta, Barcelona.

Idem (2001), La hermenéutica del sujeto, Fondo de Cultura Económica, México D.F.

Ghezzi, S. and Mingione, E. (2007), “Embeddedness, path dependency and social institutions” en Current Sociology 55(1).

Giddens, A (1979), Central Problems in Social Theory: Action, Structure, and Contradiction in Social Analysis, University of California Press, Berkeley. 
Idem (1986), The constitution of Society: Outline of the Theory of Structuration, University of California Press, Berkeley.

Idem (2005 [1991]), Modernidad e Identidad del yo. El yo y la sociedad en la época contemporánea, Península, Barcelona.

Idem (2004 [1992]), La transformación de la intimidad. Sexualidad, amor y erotismo en las sociedades modernas, Cátedra, Madrid.

Goffman, E. (1963), Stigma: Notes on the Management of Spoiled Identity, Simon \& Schuster, New York.

Idem (1974), Frame Analysis: An Essay on the Organization of Experience, Harper \& Row, New York.

Güell, P. (1999), “Subjetividad social y Desarrollo Humano” en Red de Gobernabilidad y Desarrollo, Instituto Internacional de Gobernabilidad, Barcelona.

Idem (2001), “Subjetividad social: desafío para el nuevo siglo” en Polis. Revista de la Universidad Bolivariana, $\mathrm{N}^{\circ} 2$.

Idem (2006), “Chile: cambios, miedos y convivencia” en Boletín de la Revista Latinoamericana de Desarrollo Humano, N²6, Octubre de 2006.

Idem (2007), La sociedad ha cambiado de escala ¿y ahora qué?, Temas de Desarrollo Humano Sustentable $N^{\circ} 13$.

Habermas, J. (1990 [1988]), Pensamiento Post-Metafísico, Taurus, Madrid.

Inter American Development Bank (2006), The politics of policies, Washington.

Knorr Cetina, K. (2001), “Objectual practices” en Schatzky, T (ed), The practice turn in contemporary sociology, Routledge, Londres.

Lechner, N. (2007 [1999]), “Desafíos de un desarrollo humano: individualización y capital social” en Obras Escogidas. Vol II, pp.433 - 467. Lom, Santiago de Chile.

Idem (2006 [2002]), “Las sombras del mañana. La dimensión subjetiva de la democracia” en Obras Escogidas. Vol.I, Lom, Santiago de Chile.

Lévi - Strauss, C. (1971 [1950]), “Introducción a la obra de Marcel Gauss” en Mauss, M. Sociología y Antropología, Tecnos, Madrid.

Idem (1998 [1966]), Las estructuras elementales del parentesco, Paidos, Barcelona.

Luhmann, N. (1997), Die Gesellschaft der Gesellschaft, 2 Bd, Surhkamp. 
Joas, H. (1996), The creativity of action, The University of Chicago Press, Chicago

March, J. y Olsen, J. (1993), “El Nuevo institucionalismo: factores organizativos de la vida política” en Zona Abierta 63/64.

Idem (1997), El redescubrimiento de las instituciones: la base organizativa de la política, Fondo de Cultura Económica, México D.F.

Martuccelli, D. (2007 [2002]), Gramáticas del individuo, Losada, Buenos Aires.

Idem (2007), Cambio de rumbo. La sociedad a escala del individuo, LOM, Santiago de Chile.

Mayntz, R. (2005), Politische Steuerunge-heute? Max Plank Institut für Gessellschaftforshung, Working Paper 05/01.

Mauss, M. (2000 [1950]), The Gift: The Form and Reason for Exchange in Archaic Societies, Norton \& Company, New York.

North, D. C. (1990), Institutions, Institutional Change and Economic Performance, Cambridge University Press.

Ostrom, E. (1990), Governing The Common, Cambridge: Cambridge University Press

PNUD (2002), Informe de Desarrollo Humano en Chile. Nosotros los chilenos: Un desafío cultural, Santiago de Chile.

Idem (2004), Informe de Desarrollo Humano en Chile. El poder: ¿para quién y para qué? Santiago de Chile

Idem (2009), Informe de Desarrollo Humano en Chile. La manera de hacer las cosas, Santiago de Chile.

Reckwitz, A. (2002), “Toward a Theory of Social Practices. A development in Culturalist Theorizing” en European Journal of Social Theory, Vol. 5, No. 2, 243-263

Idem (2006), Das hybride Subjekt. Eine Theorie der Subjektkulturen von der bürgerlichen Moderne zur Postmoderne, Velbrück, Göttingen.

Sen, A. (1999), Development as Freedom, Knopf, New York.

Sennett, R. (2000 [1998]), La corrosión del carácter, Anagrama, Barcelona.

Scharpf, F. (1997), Games Real Actors Play, Westview, United Kingdom. 
Schatzky, T. (1997), "Practice and actions. A wittgensteinian critique of Bourdieu and Giddens” en Philosophy of Social Sciences 27 (3)

Idem (2001), "Practice mind-ed orders” en Schatzky, T (ed), The practice turn in contemporary sociology, Routledge, Londres.

Idem (2002), The Site of the Social: A Philosophical Account of the Constitution of Social Life and Change, Pennsylvania Press, PA.

Idem (2006), “On Organizations as they happen” en Organizations Studies 27 (12).

Schelsky, H (2007), Zur soziologishen theory der institution, Bertelsmann, Dusseldorf.

Simmel, G. (2004 [1971]) Sobre la individualidad y las formas sociales. Escritos escogidos, Introducción y Edición por Donald Levine, Universidad Nacional de Quilmes, Argentina.

Swidler, A. (2001), „What anchors cultural practices“ en Schatzky, T (ed.), The practice turn in contemporary sociology, Routledge, Londres.

Taylor, Charles (1997 [1985]), “Seguir una regla” en Argumentos Filosóficos. Ensayos sobre el conocimiento, el lenguaje y la modernidad, Editorial Paidos, Barcelona.

Turner, S. (2001), “Throwing out the tacit rule book: learning and practices” en Schatzky, T (ed.), The practice turn in contemporary sociology, Routledge, Londres.

Thévenot, L (2001), "Pragmatic regimes governing the engagement with the world” en Schatzky, T (ed.), The practice turn in contemporary sociology, Routledge, Londres.

Wagner, P. (1997 [1994]), Sociología de la modernidad. Libertad y disciplina, Herder, Barcelona.

Waissbluth, M. (2008), Sistemas complejos y gestión pública, Departamento de Ingeniería Industrial, Universidad de Chile.

Wilke, H. (1997), Supervision des Staates, Suhrkamp.

Idem (2006), “La transformación de la democracia como modelo de orientación de las sociedades complejas” en Revista del Centro de Estudios Públicos $\mathrm{N}^{\circ} 102$.

Zurbriggen, C. (2006), “El institucionalismo centrado en los actores: una perspectiva analítica en el estudio de las políticas públicas” en Revista de Ciencia Política N$^{\circ} 26$. 